\title{
Physical Therapy at the postoperative of hip endoprosthesis for osteosarcoma: a case report
}

\author{
Raysa Silva Venâncio1, Tamiris Beppler Martins', Keyla Mara dos Santos', Juliete Palandi1', Larissa Sinhorim¹, Gilmar Moraes Santos'.
}

\begin{abstract}
Introduction: Osteosarcoma is the most common malignancy among musculoskeletal tumors. It can be treated for preservation member or amputation. The cases treated for preservation member have improved functionality and quality of life, however, patients with oncologic diseases exhibit symptoms of anxiety and depression. Objective: The aim of this study is to describe the role of physiotherapy in the hip endoprosthesis after surgery for osteosarcoma of a patient treated at the Clinic Physiotherapy School of the University of the State of Santa Catarina (CEFID / UDESC) and verify their quality of life, functionality and symptoms of anxiety and depression. Methods: A descriptive study through case report. The subject was assessed before and after 10 sessions of physiotherapy on the quality of life, functionality and symptoms of anxiety and depression using a standardized assessment form, the Quality of Life Assessment Questionnaire (WHOQOL-BREF), the system Functional assessment (Musculoskeletal Tumor Society Rating Scale - MSTS); of Lower Limb Function Scale (EFMI) and the Hospital Anxiety and Depression Scale (Hospital Anxiety and Depression Scale - HADS); Results and Conclusions: Physical therapy treatment proposed to the patient allowed the increase of muscle strength; increased muscle tropism; improved member functionality (65\% of EFMI); possible reduction of anxiety or depressive symptoms in HADS; presenting score $(67.31 \%)$ of the WHOQOL-BREF and (56\%) in MSTS. Thus, based on the functional, emotional and psychological outcomes, the proposed physical therapy had a positive influence on a patient's quality of life osteosarcoma at the proximal end of the left femur, underwent resection and reconstruction member with endoprosthesis.
\end{abstract}

Keywords: Physiotherapy; Osteosarcoma; Rehabilitation; Quality of life; Anxiety; Depression.

\section{INTRODUCTION}

The World Health Organization projects 27 million new cases of cancer for the year 2030 worldwide, with the highest incidence of cases in developing countries [Institute, 2014 INCA and Ministry of Health have cancer estimates for 2014 in Brazil, Daniel, 2011, Tradução e validação do instrumento Musculoskeletal Tumor Society Rating Scale (MSTS) para avaliação da função em pacientes com sarcomas ósseos dos membros inferiores]. Estimates of the Ministry of Health and the Instituto Nacional de Câncer José Alencar Gomes da Silva (INCA) indicate that, for the years of 2014 and 2015, occur 580,000 new cases of the disease. ${ }^{(1)}$ Even osteosarcoma not being among the ranking of the incidents in all regions of the country, ${ }^{(1)}$ this is the most common primary bone tumor, followed by Ewing's sarcoma. . $^{(2,3)}$

Osteosarcoma mainly affects the appendicular skeleton and in $75 \%$ of cases occur predominantly by metaphyseal and epiphyseal areas of rapid growth of long bones, with predilection to the femur. ${ }^{(2,4)}$ Currently it is performed two types of surgery for local control of the disease, amputation or limb preservation. ${ }^{(5,6)}$ the latter allows tumor resection and replacement endoprosthesis. ${ }^{(4,5)}$ Thus, in limb preservation for local control of the disease, also preserves the affected limb functionality ${ }^{(4)}$ and quality of life ${ }^{(7)}$ of the patient.

Although arthroplasty endoprosthesis promote breakthrough in the treatment of patients with osteosarcoma diagnosis, enabling the return to daily activities faster, ${ }^{(5)}$ early physiotherapy in the postoperative period is critical to the success of treatment, ${ }^{(5)}$ because the functionality, strength and range of motion are reduced after surgery. ${ }^{(5)}$

Another important factor in cancer treatment is the clinical consequences, from the diagnosis of cancer. It is observed that $20-48 \%$ of patients have positive scores for possible symptoms for anxiety or depression. ${ }^{(8,9)}$ The identification of these symptoms are extremely relevant to health professionals, since symptomatic patients do not respond to the proposed treatment.(9)

Patients who undergo tumor resection surgery may experience multiple symptoms and the disease and prolonged treatment, family ties and work may rupture ${ }^{(10)}$ Thus, it is possible that the quality of life may be negatively affected.

\footnotetext{
Corresponding author: Name: Tamiris Beppler Martins. Adress: Rua Vidal Gregório Pereira, 363, Florianópolis (SC), Brasil. E-mail: tamirismartins@outlook.com. Phone: +55 (48) 9630-4554.

${ }^{1}$ Universidade do Estado de Santa Catarina (UDESC), Florianópolis (SC), Brasil.
}

Financial support: There was no financial support for this study.

Submission date 21 September 2016; Acceptance date 18 December 2016; Publication date 30 December 2016 
Mei (2014) indicates that functional outcomes and quality of life (QOL) are similar among patients who underwent amputation and limb preservation. (7) However, Bekkering (2009) believes that the functionality and QOL are affected significantly as compared to healthy controls. ${ }^{(11)}$

In addition to the diversity of findings in the literature on quality of life, functionality and psychosocial symptoms postoperative hip endoprosthesis, there were no studies until the present moment which have described the quality of life of patients with osteosarcoma at the proximal end of the femur and endoprosthesis, after physiotherapy treatment.

\section{METHODS}

This is a descriptive study using a case report. The study was conducted at the Clínica Escola de Fisioterapia (CEF) of Centro de Ciências da Saúde e do Esporte (CEFID) of Universidade do Estado de Santa Catarina (UDESC). The patient was osteosarcoma carrier at the proximal end of the left femur, underwent resection and reconstruction member with endoprosthesis. It was treated with pre- and post-operative chemotherapy and, posteriorly, attended in the practical class of Orthopedics and Traumatology of Adult and Elderly II inserted in the eighth Physiotherapy course phase for the period May 25, 2015 to June 24, 2015.

The assessment instruments used were the medical records previously set by the standards of class of Orthopedics and Traumatology Adult and Elderly II and of CEF; the Hospital Anxiety and Depression Scale (Hospital Anxiety and Depression Scale - HADS); the Functional Assessment System (Musculoskeletal Tumor Society Rating Scale - MSTS); a Quality of Life Assessment Questionnaire (WHOQOL-BREF) and the Lower Extremity Functional Scale (LEFS).

The personal data of the patient, collected through the case report form, was filled out by the principal investigator of the study. The instrument is organized into four main blocks: a) Patient general characteristics (name, date of birth, address, occupation, clinical diagnosis and vital signs); b) history of the disease (functional kinetic diagnosis, main complaint, past illness, present illness, previous treatments, medications in use, additional tests; nature of the symptoms, result of injury); c) physical examination (inspection, palpation, mobility examination, perimetry, muscle strength, special tests); d) treatment plan (short and long-term goals, short and long term pipelines).

In the perimetry test of lower limbs held by a tape (surgically fiber tape Incoterm $1.5 \mathrm{~m}$ with $\mathrm{BMI}$ calculation) using zero as the line of the knee joint, scoring 5, 10 and $15 \mathrm{~cm}$ above and below the zero point, according to Magee. ${ }^{(11)}$

The item muscle strength, which is included in the physical examination of the patient, was assessed by the Muscular Function Test (MFT) based on Magee criteria, ${ }^{(12)}$ which defines scores from 0 to 5 , as follows: 0 no visible muscle contraction ; 1 visible contraction without range of motion; 2 there is joint movement with the elimination of gravity; 3 there is range of motion with gravity; 4 it overcomes slight resistance in range of motion and 5 it overcomes maximum resistance during range of motion.

Thus, the evaluation of the strength in this patient had some peculiarities: the knee and ankle musculature were evaluated with the patient seated, without pain; the hip was evaluated in the supine position (flexors, adductors and abductors) and prone (extenders), and the left hip flexors evaluation was approximately 45 degrees of Range of Motion (ROM) and the evaluation of left hip adductors was from slightly abduction to midline. Respecting the restriction of hip adduction and excessive flexion due to left endoprosthesis.

Regarding the special tests, it was conducted three tests to check muscle retraction of iliopsoas, rectus femoris, and gluteus medius muscle weakness: Thomas, Ely and Tredenleburg, respectively, which will be based through Magee criteria. ${ }^{(12)}$

The HADS scale contains 14 questions, of which seven evaluating anxiety (HADS-A) and seven assess depression (HADS-D). In this study will be used as cutoff point, the scores HADS > 8, because this is the score which indicates the presence of depressive and anxiety symptoms, and possible cases of depression and anxiety. ${ }^{(13)}$ The completion of the scale was done through interviews.

The MSTS is a functional assessment scale used in studies of musculoskeletal tumors, translated and validated for the Brazilian Portuguese. ${ }^{(14)}$ It measures the functional impairment of patients undergoing preserver surgery of member. It is based on relevant factors for each member and the patient for entire, consisting by 6 questions. The total maximum score is 30 points and may be converted to percentage from 0 to 100 , with higher scores indicating a better functional result. ${ }^{(14)}$

The WHOQOL-BREF, abbreviated version of WHOQOL-100, ${ }^{(15)}$ was used to assess the quality of life. It consists of 26 questions divided into four domains: Physical, Psychological, Social Relationships and the Environment. The score calculation and descriptive statistics were performed by a tool in Microsoft Excel, ranges from 0 to 100 points. The higher the score, the better the quality of life domain or total score. ${ }^{(16)}$

The LEFS is used to evaluate the functionality of the patient relative to its lower member with end skeletal muscle disorders. ${ }^{(12,17,18)}$ It was translated into Brazilian Portuguese from the Lower Extremity Functional Scale (LEFS) and composed of 20 questions with a maximum score of 80 which may be converted into a percentage from 0 to 100 . The minimal clinically significant difference is 9 points. ${ }^{(19)}$

The scales of assessment WHOQOL-BREF and MSTS were applied at the end of the treatment, i.e. only after physiotherapy. The others were applied before and after physiotherapy.

The goals of physiotherapy were keeping the left lower limb without edema and pain; reduce adhesion healing in 
scar on the left thigh; maintain muscle strength of upper limbs; increase muscle strength of hip and knee stabilizers $(R / L)$; foster care as the restriction and movement of the hip; increase muscle length of the lower limbs. ${ }^{(5)}$

To conduct, it was carried out guidelines for the elevation of the lower limbs (45) at the end of the day combined with myolymphokinetic exercises; guidelines for ROM restriction up to 90 o of the hip, restriction of adduction and internal rotation of the hip and adjustments to activities of daily living; manual techniques for scar and guidance to perform at home 1 time per day during 10 minutes; active exercises against gravity of the upper limbs; isotonic exercises isolated against gravity of hip and knee stabilizers, progressing to isotonic against resistance. ${ }^{(5)}$

The study composed of ten physiotherapy sessions, which were held twice a week during 50 minutes each, the first and the last session were reserved for collection of patient data. The other sessions are composed by physiotherapy treatment proposed by the researchers of the study, which basically involved kinesiotherapy as strengthening, stretching and manual techniques (Appendix 1).

All procedures occurred in CEF of CEFID/UDESC located in Coqueiros, Florianópolis, after signing the Consent Form.

\section{CASUISTRY}

On the first day of physiotherapy (25 May 2015), began the anamnesis from the evaluation form. In the first survey of the block gave the general characteristics of the individual: Patient W.K.C., male, 37 years old, teacher of Portuguese, married. Clinically diagnosed as osteosarcoma carrier at the proximal end of the left (L) femur in June 2014. He underwent resection and reconstruction of the member with unconventional endoprosthesis and bipolar modular type head in March 2015, being treated with chemotherapy pre and post-operative since September 2014 with its latest cycle scheduled for July 2015.

Magnetic Resonance Imaging, held in September and December 2014, revealed an expansive lesion involving the proximal portion of the femur and anterior muscles of the adjacent thigh, measuring $101 \times 44 \times 73 \mathrm{~mm}$ ( $\mathrm{L} \times \mathrm{AP} \times \mathrm{T}$ ) with compatible aspect of malignant primary neoplastic lesion with prior histological diagnosis of osteosarcoma (Figure 1).

Patient was submitted in March 2015, to resection of the left thigh tumor and reconstruction with modular femoral endoprosthesis. There were intraoperative removal Vasto Lateralis ( $12 \mathrm{~cm}$ proximal); Vastus intermedius ( $11 \mathrm{~cm}$ proximal); Adductor Longus and Magno and femoral square block with the $L$ femur and followed by reinsertion of the iliopsoas and the remaining femoral muscles in the endoprosthesis. At the end, it was done the resection of $14 \mathrm{~cm}$ of proximal $L$ femur and with surgical margin distal of $8 \mathrm{~cm}$ from the initial lesion (Figure 2).

According to the patient, he felt no pain and "felt safe to walk." The patient had performed physiotherapy postoperatively. As medicine in use, it was quoted only
Ranitidine due to cycles of chemotherapy, which were scheduled for June 8, 2015, the last held on May 25, 2015.

According to information collected, the patient was physically active before diagnosis. Regarding the nature, course and duration of symptoms, it was classified as a non-continuous pain which arises at low temperatures, in the proximal region of $L$ thigh

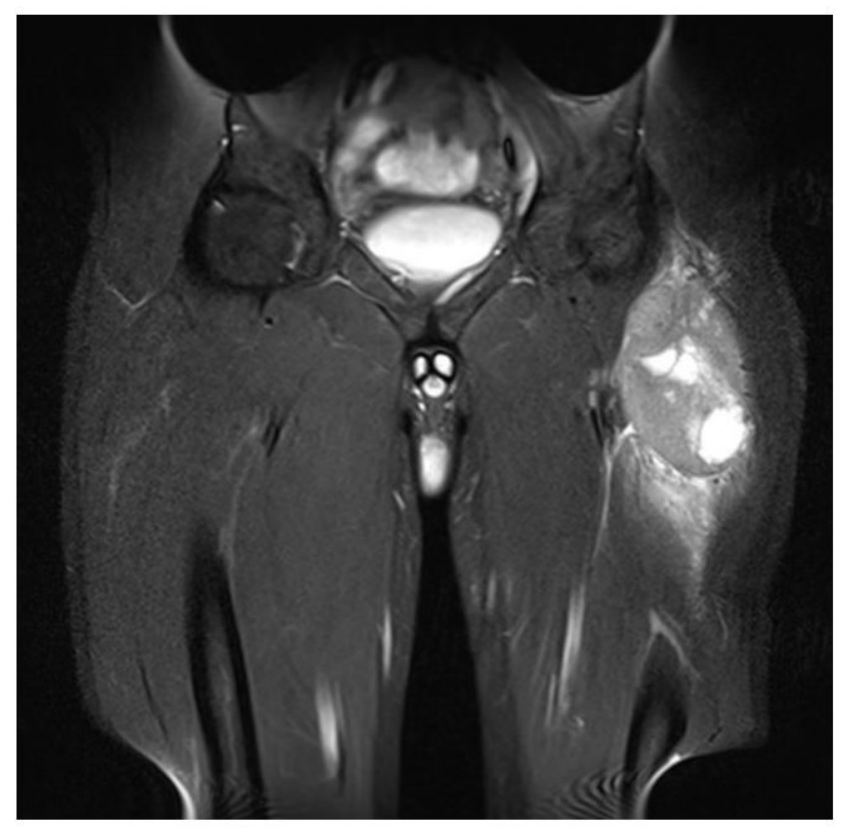

Figure 1 - MRI - Expansive lesion in the femur and adjacent musculature (2014)

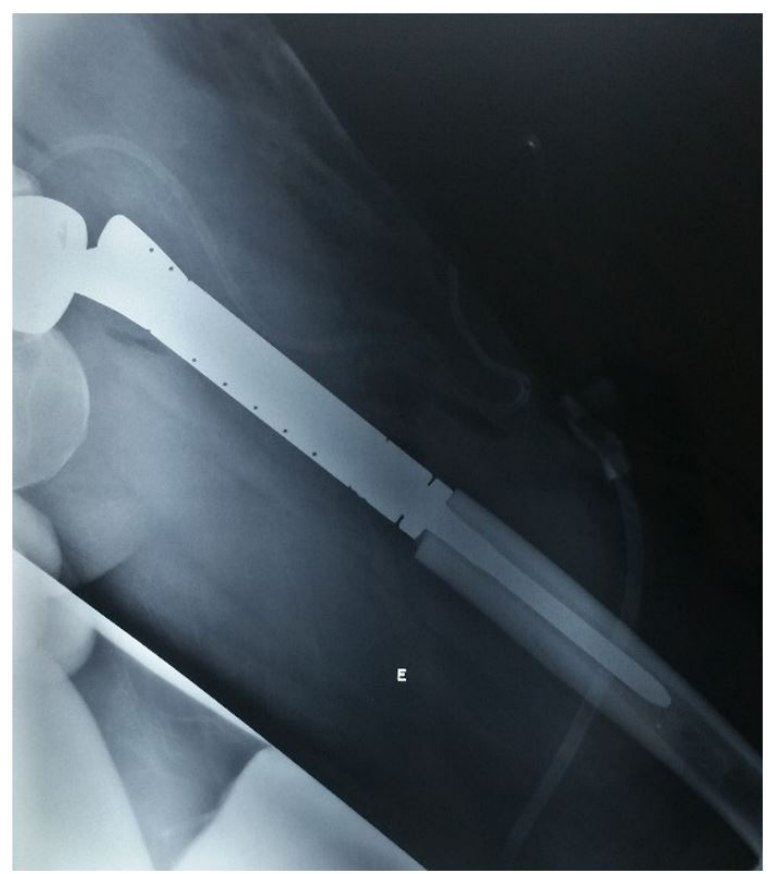

Figure 2 - X-ray on L Thigh - Postoperative of Endoprosthesis for Osteosarcoma (2015) 
As a result of the lesion, it was observed: walking with contralateral Canadian crutch, lack of full weight unloading on left lower limb (LLL); insecurity while walking; reduction in activities of daily living and muscle weakness of the hip stabilizers.

In the physical examination, the mobility, both active and passive of lower limb (LL) was reduced and according to information gathered, the same occurred due to fear and weakness. Moreover, the range of motion (ROM) is limited, since the patient is aware of the hip motion restriction (up to $90^{\circ}$ of left hip flexion) due surgical procedure.

During the inspection and palpation of the LLL, it was detected scar adhesion of the surgical wound (SW) in left thigh, no change in the proximal thigh temperature, no edema in the lower limbs and atrophy of LLL.

The values of the circumference of the lower limbs are presented in Table 1.

Data of Muscular Function Test (MFT) are shown in Table 2.

Regarding special tests, the patient data are shown in Table 3. Thomas test was not conducted to evaluate the Right Lower Limb (RLL), since it requires greater bending 90 o of the contralateral hip, which is one of post-operative restriction of hip arthroplasty.

From the evaluation, physiotherapy diagnosis was done in the patient, which reveals: Generalized muscle weakness in LLL (grade 3), major muscle retraction of left lliopsoas, $R / L$ rectus femoris and hypotrophy of $L L L$ (difference of $10 \mathrm{~cm}$ in circumference in relation to the RLL in the superior region) and, finally, scar tissue adhesion of SW.

In score of HADS questionnaire Table 4, the scores have not reached the cutoff point to consider the individual with depressive or anxiety symptoms.

Regarding the questionnaire LEFS, the patient scored 50 in the total of 80 . Presenting $62.5 \%$ of the maximum score of the lower limb functionality.

To characterize and evaluate the functional impairment of patients undergoing the preserver limb surgery after musculoskeletal tumors and their quality of life, it was applied the MSTS and WHOQOL-BREF receptively scales on the last day of treatment.

Regarding the MSTS evaluation scale, held on June 24, 2015, the individual scored 17 total of 30, representing 56\% of the desired maximum score for full functionality of patients undergoing preserver limb surgery after musculoskeletal tumors.

The quality of life scores, assessed by the WHOQOL-BREF, are shown in Figure 3.

Regarding quality of life, the total score is over half (67.31\%). The area with the highest score was the Social Relationships (75\%), on the other hand the lowest score was related to the physical domination (57.14\%).

After all evaluation, it was initiated the physiotherapy based on the behavior and goals set individually to the patient.
Table 1 - Circumference of Lower Limb - Evaluation 05/25/2015

\begin{tabular}{lccc}
\hline & Structure: Lower Limb & Right & Left \\
\hline \multirow{3}{*}{ Upper } & $15 \mathrm{~cm}$ & 46 & 41.5 \\
& $10 \mathrm{~cm}$ & 41.5 & 38 \\
Zero point: Patella & $5 \mathrm{~cm}$ & 39 & 37 \\
& & 38 & 38 \\
Lower & $5 \mathrm{~cm}$ & 34 & 34 \\
& $10 \mathrm{~cm}$ & 32.5 & 32 \\
\hline
\end{tabular}

Table 2 - Muscular Function Test (MFT) - Evaluation 05/25/2015

\begin{tabular}{lcc}
\hline \multicolumn{1}{c}{ Muscle/Movement } & Right & Left \\
\hline Knee extenders & 4 & 3 \\
Knee flexors & 4 & 3 \\
Ankle dorsiflexors & 5 & 4 \\
Ankle plantarflexors & 5 & 4 \\
Ankle inverters & 4 & 3 \\
Ankle eversion & 4 & 3 \\
Hip flexors & 3 & 3 \\
Hip adductors & 3 & 3 \\
Hip abductors & 3 & 3 \\
Hip extenders & 3 & 3 \\
Shoulder flexors & 4 & 4 \\
Elbow flexors & 5 & 5 \\
Handle extenders & 5 & 5 \\
\hline
\end{tabular}

Table 3 - Special Assessment Tests - 05/25/2015

\begin{tabular}{|c|c|c|c|}
\hline Performed Test & Goal & Negative & Positive \\
\hline Thomas & Left Illiopsoas muscle contraction & & $X(L)$ \\
\hline Ely & $\begin{array}{l}\text { Rectus femoris muscle } \\
\text { contraction }\end{array}$ & & $X(R / L)$ \\
\hline Tredenleburg & Medius gluteus muscle weakness & & $X(R / L)$ \\
\hline
\end{tabular}

Table 4 - HADS Questionnaire - Evaluation 05/25/2015

\begin{tabular}{cc}
\hline Dominance & Evaluation \\
\hline Anxiety & 0 \\
Depression & 4 \\
Total & 4 \\
\hline
\end{tabular}

There were four of eight sessions reserved for intervention due to chemotherapy cycles occurring within the study period. In the treatments, the conduct remained as: collection of Initial Vital Signs (IVS), manual techniques to release scar tissue adhesion in left thigh; R/L patellar mobilization; lower limb strengthening exercises for entire, both isometric and isotonic concentric and eccentric (maximum load of $1 \mathrm{~kg}$ ); standing weight-training, ranging in latero-lateral and anteroposterior 
and step forward, side and behind statically; stretching knee extensor muscles; collection of the Final Vital Signs (FVS). Patient was reevaluated on June 24, 2015 and was delivered to the home guidelines in relation to post physiotherapy care.

\section{RESULTS}

During inspection and palpation, after 10 physiotherapy sessions, the LLL was detected reduction scar adhesion of the surgical wound (SW) in left thigh. The absence of: changing in proximal left thigh temperature, edema in LL and hypotrophy of LLL, remained.

In the last session, perimetry of the LL was reevaluated, the results are shown in Table 5, as well as the range of values when compared to the initial assessment. It may be observed an average variation of $0.57 \mathrm{~cm}$ in the circumference of RLL and $1.92 \mathrm{~cm}$ as LLL.

The revaluation was also performed the MFT. This, and the strength degree of variation, when compared to the initial assessment, may be seen in Table 6. It is possible to observe that all the LLL presented gain in graduation muscle strength $(+1)$ after physiotherapy, as well as the flexor muscles of the left shoulder musculature. The musculature of flexors and right hip extensors obtained greater variation in the graduation of muscle strength (+2). The stabilizing muscles of the right ankle maintained the graduation of strength, as well as $\mathrm{R} / \mathrm{L}$ elbow flexors and R/L wrist extensors.

As for special tests, the values remained unchanged after physiotherapy compared to the LLL. When compared to baseline values, special tests Ely and Trendenleburg became negative in the RLL.

The results obtained in the HADS questionnaire (Figure 4), the scores showed +3 points change to the domain anxiety, and -1 point for the domain depression, resulting in an increase in the total score of 4 to 6 . Still, the cutoff point for considering the individual with depressive symptoms or anxiety was not reached.

Regarding the LEFS questionnaire, the revaluation, the patient score was 52 in the total of 80 , which is, when compared to the evaluation, there was a positive increase of 2 points. Presenting $65 \%$ of the maximum score of the lower limb functionality, and $2.5 \%$ increase in the total score.

Figure 5 shows the comparison between the data collected and obtained after physiotherapy treatment.

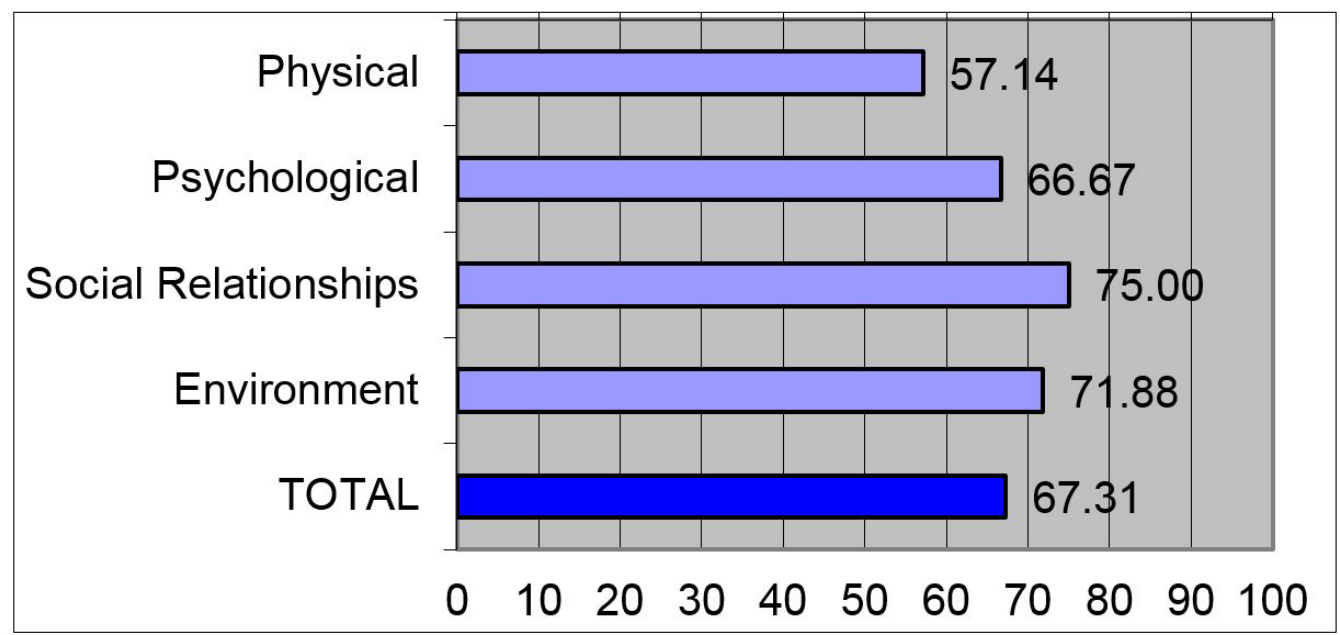

Figure 3 - WHOQOL-BREF questionnaire - Evaluation 06/24/

Table 5 - Circumference of lower limbs - Revaluation 06/24/2015 and Variation (cm) after physiotherapy treatment

\begin{tabular}{|c|c|c|c|c|c|c|c|}
\hline \multirow{2}{*}{\multicolumn{2}{|c|}{$\begin{array}{l}\text { Circumference }(\mathrm{cm}) \\
\text { Structure: Lower Limb }\end{array}$}} & \multicolumn{2}{|c|}{$\begin{array}{l}\text { Evaluation } \\
05 / 25 / 2015\end{array}$} & \multicolumn{2}{|c|}{$\begin{array}{l}\text { Revaluation } \\
06 / 24 / 2015\end{array}$} & \multirow{2}{*}{$\begin{array}{c}\begin{array}{c}\text { Variation } \\
(\mathrm{cm})\end{array} \\
\text { Right }\end{array}$} & \multirow{2}{*}{$\begin{array}{c}\begin{array}{c}\text { Variation } \\
(\mathrm{cm})\end{array} \\
\text { Left }\end{array}$} \\
\hline & & Right & Left & Right & Left & & \\
\hline \multirow{3}{*}{ Upper } & $15 \mathrm{~cm}$ & 46 & 41.5 & 48 & 43.5 & +2 & +2 \\
\hline & $10 \mathrm{~cm}$ & 41.5 & 38 & 43 & 40 & +1.5 & +2 \\
\hline & $5 \mathrm{~cm}$ & 39 & 37 & 40 & 38 & +1 & +2 \\
\hline \multicolumn{2}{|c|}{ Zero: Line knee joint } & 38 & 38 & 38 & 38 & 0 & 0 \\
\hline \multirow{3}{*}{ Lower } & $5 \mathrm{~cm}$ & 34 & 34 & 39 & 38 & 0 & +4 \\
\hline & $10 \mathrm{~cm}$ & 32.5 & 32 & 35 & 35 & +0.5 & +3 \\
\hline & $15 \mathrm{~cm}$ & 34 & 32.5 & 33 & 33 & -1 & +0.5 \\
\hline
\end{tabular}


Table 6 - Graduation of lower limbs muscle strength of the pre and post physiotherapy treatment - Revaluation 06/24/2015 and Post Physiotherapy Treatment Variation

\begin{tabular}{|c|c|c|c|c|c|c|}
\hline \multirow{2}{*}{ Muscle/ Movement } & \multicolumn{2}{|c|}{ Eva. 25/05/2015 } & \multicolumn{2}{|c|}{ Reva. 24/06/2015 } & \multirow{2}{*}{$\begin{array}{c}\text { Variation } \\
\text { Right }\end{array}$} & \multirow{2}{*}{$\frac{\text { Variation }}{\text { Left }}$} \\
\hline & Right & Left & Right & Left & & \\
\hline Knee extenders & 4 & 3 & 5 & 4 & +1 & +1 \\
\hline Knee flexors & 4 & 3 & 5 & 4 & +1 & +1 \\
\hline Ankle dorsiflexors & 5 & 4 & 5 & 5 & 0 & +1 \\
\hline Ankle Plantarflexors & 5 & 4 & 5 & 5 & 0 & +1 \\
\hline Ankle Inverters & 4 & 3 & 4 & 4 & 0 & +1 \\
\hline Ankle Eversion & 4 & 3 & 4 & 4 & 0 & +1 \\
\hline Hip flexors & 3 & 3 & 5 & 4 & +2 & +1 \\
\hline Hip Adductors & 3 & 3 & 4 & 4 & +1 & +1 \\
\hline Hip abductors & 3 & 3 & 4 & 4 & +1 & +1 \\
\hline Hip Extenders & 3 & 3 & 5 & 4 & +2 & +1 \\
\hline Shoulder flexors & 4 & 4 & 5 & 5 & +1 & +1 \\
\hline Elbow flexors & 5 & 5 & 5 & 5 & 0 & 0 \\
\hline Handle extenders & 5 & 5 & 5 & 5 & 0 & 0 \\
\hline
\end{tabular}

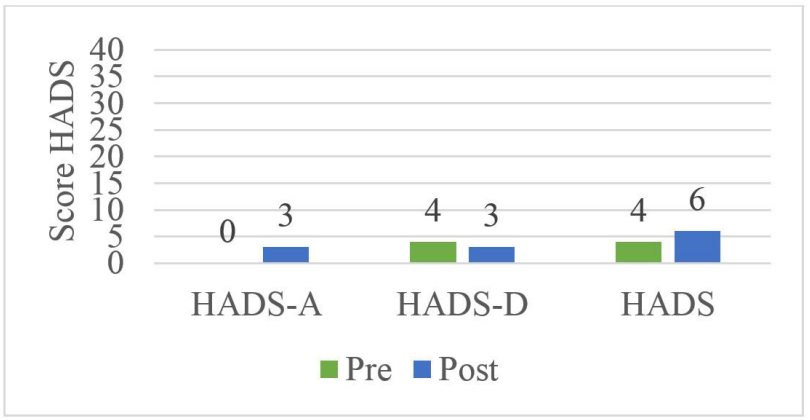

Figure 4 - HADS questionnaire - Pre and post-intervention data

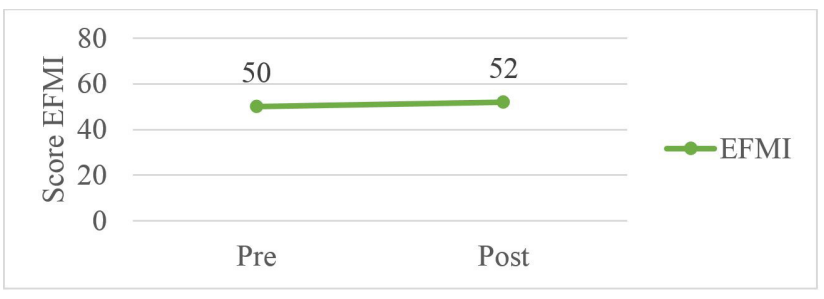

Figure 5 - LEFS Questionnaire - Data pre and post-intervention

\section{DISCUSSION}

The aim of the study was to evaluate the role of physiotherapy in the postoperative period of hip endoprosthesis in an osteosarcoma patient, as well as checking the quality of life, functionality and symptoms of anxiety and depression.

Considering the results, it was observed overall improvement in several orthopedic aspects related to quality of life and limb function. Among them, the increase in muscle strength and muscle tropism; absence of depressive or anxiety symptoms; improvement of the limb functionality and quality of life.

Patients in Cancer treatment have reduced daily living and professionals activities, which causes significant restriction to exercise. ${ }^{(5,20)}$ The reduction of exercises, such as the daily living activities, are predisposing factors to the reduction of muscle trophism and strength. ${ }^{(21)}$ Moreover, during the resection of the tumor, there is safety margin for local control of the disease. These factors lead to a reduction of the circumference of the limbs, mainly the affected limb compared to the healthy. These findings corroborate those observed in the studied patient before the physiotherapy treatment.

Additionally, the muscle strength and trophism are reduced in patients after surgery of limb preservation by endoprosthesis. However, studies note that individualized exercises $^{(20)}$ and physiotherapy protocols increase muscle strength, ${ }^{(5)}$ producing positive impact in patients with malignant bone tumor. ${ }^{(20)}$ It is assumed that the circumferential increase of lower limbs in perimetry is related to the increase in trophism and consequent muscle strength. Therefore, the proposed physiotherapy was beneficial to the patient in the study because strength and muscle tropism were obtained, which therefore provides a faster return to functional activities. (20)

Regarding functionality after limb salvage, studies report better functioning compared to amputation, but the differences are not significant. ${ }^{(7)}$ In the present study, the functionality, measured by pre and post LEFS physiotherapy showed positive variance of $2.5 \%$. It is considered, therefore, improves the limb functionality with endoprosthesis after the intervention, making $65 \%$ of the maximum score for lower limb 
functionality. Thus, it is suggested that the physiotherapy is able to change the function of the operated limb.

Studies using the MSTS showed better functional outcomes in patients post limb preservation. ${ }^{(7)}$ The patient of the present study score of $56 \%$ in MSTS, thus, it may suggest that the function of the musculoskeletal limb is not reduced after tumor (> $50 \%$ of the scale).

Regarding anxiety and depression in patients with cancer, studies show high incidence in both in independent and mixed dominions. ${ }^{(8,9,22)}$ The use of the HADS to evaluate anxiety and depression, shows good performance for sub-scale anxiety (HADS-A) when compared to depression (HADS-D). ${ }^{\left({ }^{8}\right)}$ The patient in the study did not present criteria for depressive or anxiety symptoms. However there was an increase in the HADS-A score of 4 points. It is assumed that the alteration should be linked to the chemotherapy, which occurred in the same week in which the scale was reapplied. Therefore, cancer survivors report that fatigue is one of the most distressing symptoms of the treatment, more than pain, nausea and vomiting $^{(23)}$ increasing anxiety symptoms.

Finally, the cancer patients quality of life, in a meta-analysis, shows to be significantly better in those who underwent limb salvage than in those who underwent post osteosarcoma amputation. ${ }^{(3)}$ Which confirms the evaluation obtained in this study on a carrier osteosarcoma after endoprosthesis, which reveals score of $67.31 \%$ in the QV WHOQOL-BREF questionnaire.

In Psychology and Social Relations domains, the patient who underwent endoprosthesis (limb preservation), scored $66.67 \%$ and $75 \%$, respectively. Therefore, it is observed a considerable psychological burden, which may be due to concern about the return of tumor, ${ }^{(3)}$ however, it obtained a high social scale, because in the case of limb amputation, the social consequences could be higher ${ }^{(3)}$ reducing the domain Social Relationships.

\section{CONCLUSION}

The patient with bone tumor in proximal end of the femur showed a higher quality of life than the average score on WHOQOL-BREF scale, member of functionality after Musculoskeletal tumor (MSTS) and within the expected and absence of depressive symptoms or anxiety (HADS).

Physiotherapy treatment proposed for this case, enabled increase in muscle function, circumference of lower limb and lower limb functionality.

\section{AUTHOR'S CONTRIBUTIONS:}

RSV, TBM: Design and development (provided the idea for research or article and created the hypothesis); RSV: methodological design (planning methods to generate the result); TBM, KMS: Supervision (responsible for organizing and execution of the project and writing of the manuscript); RSV: Collection and processing of data (responsible for experiments, patients and organization of data); RSV: Analysis / interpretation (responsible for statistical analysis, evaluation and presentation of results); RSV, TBM, KMS: Literature survey (participated in the bibliographical research and articles survey); RYS, KMS, TBM: Wording (responsible for writing a substantive part of the manuscript); GMS: Critical revision (responsible for reviewing the intellectual content of the manuscript before final submission).

\section{CONFLICTS OF INTEREST:}

The authors declare that they have no conflicts of interest in the research.

\section{REFERENCES}

1 Inca. INCA e Ministério da Saúde apresentam estimativas de câncer para 2014 no Brasil. INCA. Rio de Janeiro. 2014; 0-122.

2 Van Driel M, Van Leeuwen JP. Cancer and bone: a complex complex. Arch Biochem Biophys. 2014; 561: 159-66.

3 F jiang, GL, Y shi, F zhou. A meta-analysis of limb-salvage versus amputation in the treatment of patients with Enneking $\neq U$ pathologic fracture osteosarcoma. Indian Journal of Cancer, 2014.

4 Mendonça SMH, Cassone AE, Brandalise SR. Functional assessment of patients with bone sarcomas submitted to surgical treatment using total or partial prosthesis in replacement of the distal femoral end. Acta ortop. bras. 2008; 16(1): 13-18. ISSN 1413-7852.

5 Tsai LY, Jesus-Garcia Filho R, Petrilli AS, Korukian M, Viola DCM, Petrilli $M$, et al. Protocolo Fisioterapêutico Em Pacientes Submetidos À Endoprótese Não Convencional De Joelho Por Osteossarcoma: Estudo Prospectivo. Revista Brasileira de Ortopedia. 2007;42.

6 Durr, HR, et al. [Resection margins in bone tumors: what is adequate?]. Unfallchirurg. 2014; 117(7): 593-9. ISSN 0177-5537.

7 Mei, J. et al. Functional outcomes and quality of life in patients with osteosarcoma treated with amputation versus limb-salvage surgery: a systematic review and meta-analysis. Arch Orthop Trauma Surg. 2014; 134(11): 1507-16. ISSN 0936-8051.

8 Bergerot, C. D. et al. Assessment of anxiety and depression in cancer patients: a psychometric comparison. Psico-USF. 2014;19(2): 187-197. ISSN 1413-8271.

9 Kurt Kroenke, MDA, et al. The Patient Health Questionnaire Somatic, Anxiety, and Depressive Symptom Scales: a systematic review. General Hospital Psychiatry. 2010; 32(4): 345-359.

10 Postma A, Kingma A, De ruiter JH, Schraffordt Koops H, Veth RP, Goëken LN, Kamps WA. Quality of life in bone tumor patients comparing limb salvage and amputation of the lower extremity. J Surg Oncol. 1992; 51(1):47-51.

11 Bekkering, W. P. et al. Quality of life in young patients after bone tumor surgery around the knee joint and comparison with healthy controls. Pediatr Blood Cancer.2010; 54(5): 738-45. ISSN 1545-5009.

12 Mageee DJ. Avaliação musculoesquelética. 4. Barueri: São Paulo: 2005.

13 Botega NJ. et al. Transtornos do humor em enfermaria de clínica médica e validação de escala de medida (HAD) de ansiedade e depressão. Rev. Saúde Pública. 1995; 29(5): 359-363. ISSN 0034-8910.

14 Rebolledo DCS. Tradução e validação do instrumento Musculoskeletal Tumor Society Rating Scale (MSTS) para avaliação da função em pacientes com sarcomas ósseos dos membros inferiores. Dissertação USP/FM - São Paulo, 2011.

15 Organization WH. WHOQOL-BREF: introduction, administration, scoring and generic version of assessment, 1996.

16 Pedroso BEA. Cálculo dos escores e estatística descritiva do WHOQOL-bref através do Microsoft Excel. Revista Brasileira de Qualidade de Vida. 2010; 2: 31-36, 2010.

17 Stratford PW, E. A. Validation the LEFS on patients with total joint arthroplasty. Physiother Can. 2000; 52(105).

18 Healthcare E. Lower Extremity Functional Scale (LEFS): Emory Physical Therapy. 1999. Disponível em: < https://www.emoryhealthcare.org/ physical-therapy/pdf/hip-lefs.pdf >. Acesso em: junho.

19 Database RM. Rehab Measures: Lower Extremity Functional Scale. 2013. Disponível em: < http://www.rehabmeasures.org/Lists/RehabMeasures/ DispForm.aspx?ID=1113 >. Acesso em: jun. 
20 Winter CC. et al. The effect of individualized exercise interventions during treatment in pediatric patients with a malignant bone tumor. Support Care Cancer. 2013; 21(6): 1629-36.

21 Organization WH. Global recommendations on physical activity for health WHO: World Health Organization. 2014; 0-58.
22 Ballenger JC, Davidson JRT, Lecrubier Y, Nutt DJ, Jones RD, Berard RMF. Consensus statement on depression, anxiety, and Oncology. Journal of Clinical Psychiatry. 2001; 62(8): 64-67.

23 Berger AM. et al. Cancer-Related Fatigue. Journal of the National Comprehensive Cancer Network. 2010; 01-08. Disponível em: < http:// www.jnccn.org/content /8/8/904.extract >. 


\section{APPENDIX 1 - PHYSIOTHERAPY TREATMENT PROPOSED BY THE RESEARCHER OF THE STUDY, WITH OBJECTIVES AND CONDUCTS.}

\section{Objectives:}

- Maintain the left lower limb free of edema and pain;

- Reduce scar adhesion of the scar tissue in the left thigh;

- Maintain muscle strength of the upper limb;

- Increase muscle strength of hip and knee stabilizers (right/left);

- Promote care regarding restraint and movement of the hip;

- Increase muscle length of the lower limb.

\section{Conduct:}

- Guidelines for elevation of the lower limbs (450) at the end of the day allied to myolonokokinetic exercise;

- Guidelines for range of motion restriction up to $90^{\circ}$ of the hip, restriction of the adduction and the internal rotation of the hip and adaptations to activities of daily living;

- Manual techniques for scarring and guidelines to perform at home once a day by 10 minutes;

- Active exercises against the severity of upper limbs;

- Isolated isotonic exercises against the severity of hip and knee stabilizers, progressing to isotonic against the resistance. 